\title{
Control of quality and modes of power supply systems using contactless devices
}

\author{
Erkin Abduraimov ${ }^{1}$, Dilshad Khalmanov ${ }^{1}$, Moldagali Peysenov ${ }^{1}$, Nargiza Khamidova ${ }^{1}$ \\ ${ }^{1}$ Tashkent State Technical University named by Islam Karimov, Tashkent, Uzbekistan
}

\begin{abstract}
The article discusses the issues of creating contactless switching devices for automatic quality control and operation modes of power supply systems, using the developed contactless thyristor voltage relays, characterized by high reliability and speed, combining a sensitive system and a powerful final controlling element. Schemes with operating principles and experimental characteristics are given. It is proposed to use it to automatically turn on or off the booster transformer winding when the input voltage changes to maintain the rated voltage of electricity consumers, as well as to create a power regulator for capacitor banks of reactive energy compensating devices.
\end{abstract}

\section{Introduction}

Electricity as a special type of product, with various quality indicators, which are used to judge its suitability in a production environment. One of the important quality indicators is the stability of the effective voltage value. Using special technical means of regulation, transformers with load regulation or booster transformers, it is possible to achieve an improvement in the quality of voltage at consumers. In this case, it becomes necessary to change the number of turns of the primary windings of the transformers. For this purpose, we recommend using non-contact power devices that are controlled by means of non-contact voltage relays. Contactless relay circuits allow switching the power thyristor with improved starting modes, namely, when a sinusoidal current passes through zero.

Achievements in power semiconductor electronics have now made it possible to master a new class of electrical devices - contactless switching semiconductor equipment CSSE [4-5].

For power supply systems (PSS) of industrial facilities, it is especially important to create a high-voltage CSSE with alternating voltage of $6-10 \mathrm{kV}$, because at this voltage stage, numerous responsible consumers and, above all, a powerful motor load are included. The specified equipment in combination with equipment of traditional electromechanical design allows solving numerous problems of power supply of industrial facilities, raising the technical level of modern power supply systems to a qualitatively new level. Nocurrent switching, synchronous control, high performance and an almost unlimited resource open up fundamentally new possibilities in power supply engineering [10-11].

At the same time, the high-voltage CSSE makes it possible to solve the problem of high-speed current limitation, to create, in particular, reactor less $6-10 \mathrm{kV}$ networks with a short-circuit power of up to 1500 MVA; limit shock emergency currents, reduce thermal and dynamic effects on the elements of the PSS; to simplify the connection of electrical receivers with an abruptly alternating shock load; to ensure self-starting of large electrical machines and transfer of synchronous motors without extinguishing their field to a backup source; control the reactive elements of the network reactors, capacitor banks; create ring networks with a voltage of $0.4 ; 6 ; 10 \mathrm{kV}$ and rational use of transformer power; improve the quality of electricity in distribution networks; reduce capital costs for the construction of a PSS. [12-14].

The problem of creating reliable and economical regulating and switching devices and devices as elements of electrical equipment for alternating current circuits is very important for ensuring uninterrupted operation, clarity and speed of operation of power devices.

The contact devices and apparatuses widely used for these purposes have the following disadvantages:

$>$ arcing at the contacts at the moment of switching and the need for appropriate volumes for arcing;

$>$ low electrical and mechanical wear resistance of contacts, especially in polluted air and high humidity;

$>$ large inertia of the system when switching on and off;

$>$ vibration and burning of contacts from inrush currents;

$>$ limited frequency of switching on due to air ionization in the area of contact breakage and their heating;

$>$ limited service life and relatively low reliability;

$>$ insufficient vibration and shock resistance;

$>$ difficulty performing at increased voltages, currents and network frequency;

$>$ significant power consumed by control circuits;

$>$ the presence of operating costs for maintenance;

$>$ overvoltage at the moment of switching on;

$>$ non-simultaneous switching on in all phases; 
$>$ a certain position of the apparatus, determined by its design;

$>$ the impossibility of superfast shutdown when a person gets under voltage;

$>$-the presence of noise.

These disadvantages are constraining factors in increasing the productivity of objects equipped with contact switching and control electrical equipment.

Currently, the industry produces many types of thyristors. They are used in both electronics and high-current electrical engineering. Due to their remarkable characteristics, the field of application of thyristors is very wide. The thyristor has all the advantages of semiconductor devices. Its dimensions and weight in relation to power are very small. It is capable of operating both at low $\left(-50,-60^{\circ} \mathrm{C}\right)$ and at elevated (over 100 $\circ$ C) temperatures. He is always ready for action. Energy loses in it are negligible. The efficiency of the device itself exceeds $99 \%$. The energy required for control is hundreds of thousands of times less than the energy that can be controlled using a thyristor. When carefully manufactured, this device operates with a high degree of reliability. It has no moving parts and no vacuum. During operation, it practically does not require maintenance. The range of currents (from $\mathrm{mA}$ to thousand A), the range of voltages (up to $1000 \mathrm{~V}$ and more), the speed of action (up to fractions of microseconds) - all this makes the thyristor an indispensable device in many areas of technology [15-16].

In non-contact semiconductor electrical equipment based on thyristors, the noted disadvantages of contact electrical equipment are excluded and there are a number of significant advantages:

$>$ system speed and good controllability; -practical inertia;

$>$ the possibility of limiting the dynamic overload of the actuators at the moment of switching on (shock less start);

$>$ great selectivity in defenses;

$>$ increased service life and reliability;

$>$ technological design, no precise assembly requirements;

$>$ easy to implement reverse and adjustable electrodynamics braking;

$>$ practically unlimited switching frequency;

$>$ the ability to use at frequencies up to $1000 \mathrm{~Hz}$;

$>$ the possibility of regulating the output parameters according to a given law, including smooth acceleration of the electric drive;

$>$ the possibility of limiting the short-circuit current when using forced commutation;

$>$ possibility of overvoltage reduction at the moment of load switching;

$>$ the possibility of using devices of the same type in networks of various voltages by replacing thyristors with thyristors of a different class [1-3].

\section{Non-contact devices for switching the booster transformer windings}

Consider a circuit of a contactless switching device based on a transformer contactless voltage relay. The implementation of a contactless thyristor device for turning on and off the winding of the booster transformer according to the specified scheme provides the best weight and dimensions and high reliability (Fig.1).

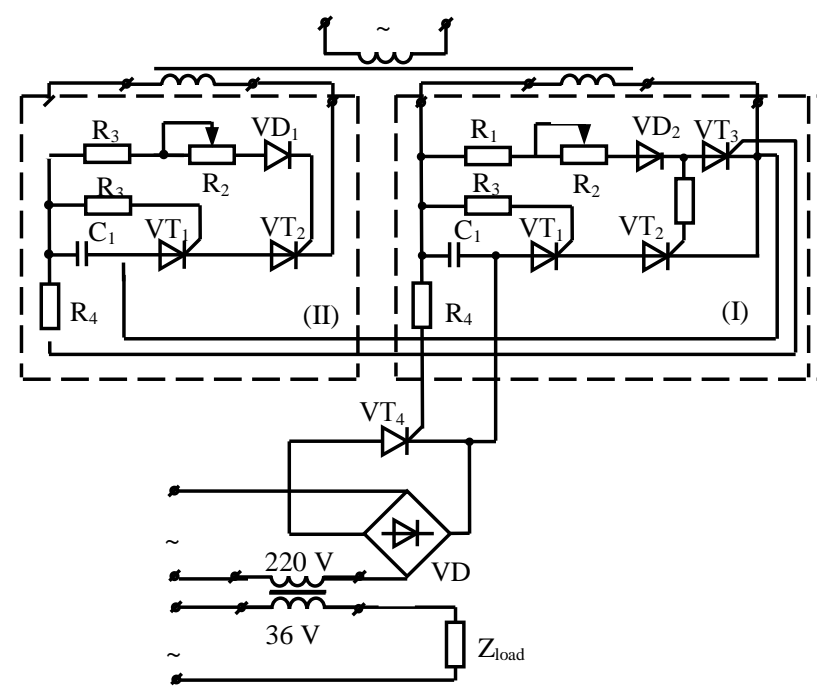

Fig. 1. Diagram of an automatic contactless switching device.

The winding of the booster transformer is connected to the network by means of the diode bridge VD, the controlled power thyristor $\mathrm{VT}_{4}$ is included in the diagonal of the diode bridge. To the control electrode of the power thyristor, control signals are fed through the resistor $\mathrm{R}_{4}$ from the plates of the capacitor $\mathrm{C}_{1}$ (I-relay), which in turn is connected to the secondary winding of the low-power transformer through two low-power controlled thyristors $\mathrm{VT}_{1}, \mathrm{VT}_{2}$. [4,5]

The control signal for thyristor $\mathrm{VT}_{1}$ is supplied from the secondary winding of a low-power transformer through a series-connected $\mathrm{R}_{3}$. The control signal for the thyristor $\mathrm{VT}_{2}$ is supplied from the secondary winding of a low-power transformer through the series-connected $\mathrm{R}_{1}, \mathrm{R}_{2}$ and the diode $\mathrm{VD}_{2}$, and also through the resistor R5, since the thyristor VT3 is closed. Disconnection of the booster transformer winding from the network is carried out due to the action of the second voltage relay (II), containing a limiting resistor R4 through which a signal is supplied to the control electrode of the $\mathrm{VT}_{3}$ thyristor. Opening the thyristor $\mathrm{VT}_{3}$ will turn off the control signal of the thyristor $\mathrm{VT}_{2}$ (I-relay), thereby closing $\mathrm{VT}_{2}$ and this will turn off the control signal of the power thyristor $\mathrm{VT}_{4}$. The rest of the relay circuit (II) is performed in the same way as for relay (I). Variable resistors $R_{2}$ in both relays are used to adjust the relay pickup setting.

In fig. 2. shows the characteristics of the "input-output" contactless automatic switching device.

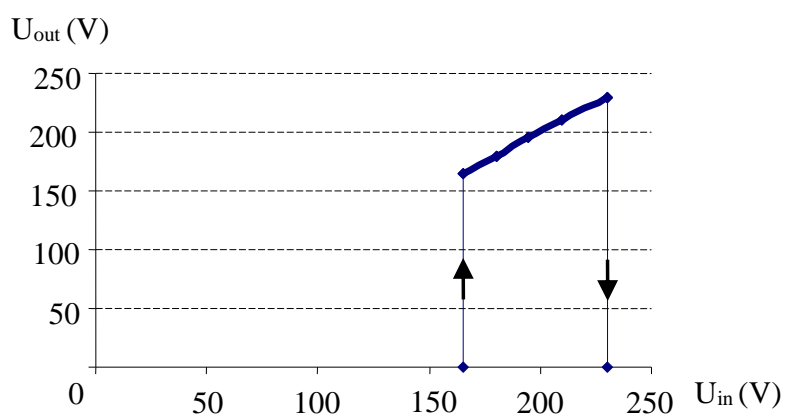

Fig. 2. Characteristic "input-output" contactless switching device. 


\section{Non-contact thyristor devices for switching on and off capacitor units}

The previously described switching device can be used to turn on and off a capacitor bank, that is, to create an automatic power regulator for capacitor banks. For artificial compensation of reactive power, sometimes called "lateral" compensation, special compensating devices are used, which are sources of reactive energy of a capacitive nature.

The main standard indicator characterizing the reactive power consumed by an industrial enterprise was the weighted average power factor.

Weighted average power factor for time $t$

$$
\cos \varphi=\frac{W_{a t}}{\sqrt{W_{a t}^{2}+W_{p t}^{2}}}
$$

where $\boldsymbol{W}_{\boldsymbol{a}}$ and $\boldsymbol{W}_{\boldsymbol{p} t}$ - respectively, the consumption of active and reactive electricity for the considered period of time.

The requirements of the power supply organization were such that at the inputs of the enterprise, the value of $\cos \varphi$ weighted average should have been in the range of 0.92 0.95 .

However, in terms of reactive power compensation, the enterprises were not interested in disconnecting the installed WHB during the hours of minimum loads. In this regard, overcompensation of reactive power was often observed in the supplying power system. Overcompensation is an excess reactive power generated by a compensating installation during periods of lower loads (at night, during lunch breaks, on non-working days and holidays, etc.) and transmitted to the power grid. The result of overcompensation was an increase in the total losses of power and energy in electrical networks and the complication and rise in the cost of voltage control devices.

A non-contact thyristor device for switching on capacitor banks, containing a diode bridge, in the diagonal of which a controlled power thyristor is included, and the diode bridge is connected to the network in series with the capacitor banks. To the control electrodes of the power thyristor, control signals are fed through the resistor and the thyristor part of the first voltage relay (I). The diode part is connected through resistors to the plates of the capacitor, which in turn is connected to the network through two series-connected lowpower controlled thyristors. The control signal for one of them is supplied from the network through a series-connected diode and a resistor, and for the second through a resistor. The capacitor is disconnected from the network due to the action of the second voltage relay (II), the diode circuit of which is connected to the capacitor plates of the second relay through a resistor, and the thyristor circuit is connected between the connection point of the two resistances of the diode circuit and the capacitor plate of the first relay. The rest of the second relay circuitry is done as in the first relay.

Implementation of a non-contact thyristor device for switching on and off capacitor banks according to the specified scheme provides the best weight and dimensions and high reliability.

Figure 3. shows a circuit diagram of a non-contact thyristor device for switching on and off capacitor banks.
The device contains a diode bridge connected to the network in series with a capacitor $\mathrm{C}_{3}$, a controlled thyristor $\mathrm{T}_{5}$ is included in the diagonal of the bridge, control signals are fed to the control electrode of the power thyristor through a resistor $\mathrm{R}_{6}$ and a thyristor circuit.

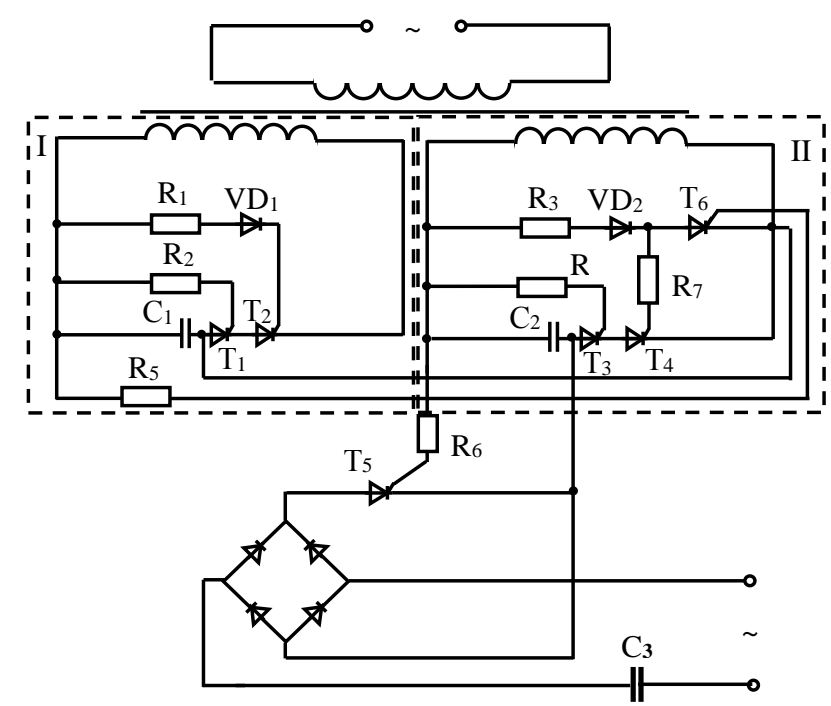

Fig. 3. Scheme of automatic switching on and off of a capacitor bank.

The diode circuit is connected through resistors $\mathrm{R}_{5}$ to the plates of the capacitor $\mathrm{C}_{1}$, which is connected in series with two low-power controlled thyristors $\mathrm{T}_{1}, \mathrm{~T}_{2}$. The control electrode of the low-power thyristor $\mathrm{T}_{2}$ is connected to the network through the series-connected resistor $\mathrm{R}_{1}$ and the diode $\mathrm{VD}_{1}$, and the control electrode of the low-power thyristor $T_{1}$ is connected through the resistor $R_{2}$ to the first plate of the capacitor $\mathrm{C}_{1}$. The diode part is connected through a series-connected limiting resistor $\mathrm{R}_{5}$ to the plates of the capacitor $\mathrm{C}_{2}$, which in turn is connected to the network through two series-connected low-power controlled thyristors $\mathrm{T}_{3}, \mathrm{~T}_{4}$. The control signal to these thyristors is supplied in the same way as in the circuit of the first relay.

Figure 4. shows the characteristic of voltage change inputoutput of a non-contact thyristor device.

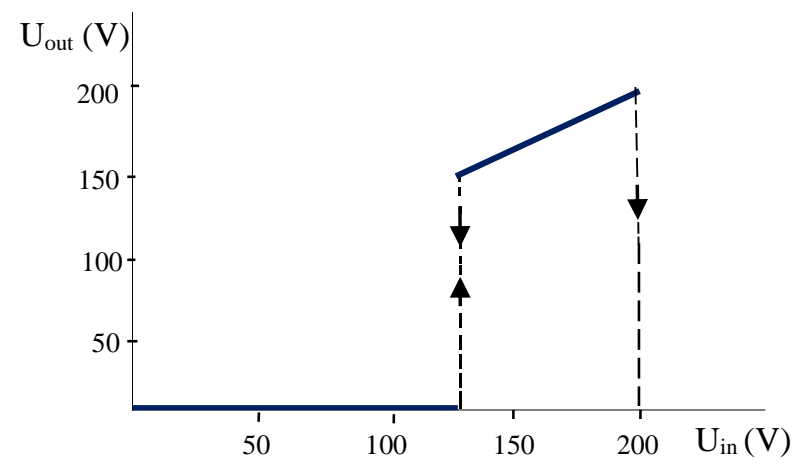

Fig. 4. Characteristic "input-output" of a non-contact device.

A non-contact thyristor device for switching on and off capacitor banks works as follows. When a certain value of the input voltage is reached, the trigger signal on the control electrode of the second relay will be sufficient to open the 
thyristor $\mathrm{T}_{4}$, and the operating current of this thyristor opens the thyristor $T_{3}$ in a jump. After opening thyristors $T_{3}, T_{4}$, the capacitor $\mathrm{C}_{2}$ is charged. From the plates of the capacitor $\mathrm{C}_{2}$, through the resistor $R_{6}$, an unlocking signal is supplied to the control circuit $T_{5}$ of the power thyristor $T_{2}$, which, opening, turns on the capacitor $\mathrm{C}_{3}$ into the network. The trigger moment of the thyristors $T_{3}, T_{4}, T_{5}$ is regulated by selecting the parameter of the resistors $R_{3}$ and $R_{4}$.

With an increase in the input voltage, the capacitor is disconnected from the network due to the action of the first voltage relay. When the first is turned on, closing the control circuit of the thyristor $\mathrm{T}_{6}$ and this will lead to the disconnection of the second relay. This leads to the disconnection of the power thyristor $\mathrm{T}_{5}$ and the opening of the capacitor unit [6-9].

Figure 4. shows the characteristic of voltage change inputoutput of a non-contact thyristor device.

\section{Conclusions}

Thus, we offer contactless thyristor devices for automatic control of modes and quality of electricity in PSS, in particular, contactless branch switches for power and booster transformers, as well as contactless switching and regulation of parameters of reactive elements in PSS (tanks, reactors), reactive power sources. [10, 11, 12, 13, 14, 15, 16]

\section{References}

1. Kudrin B.I. - Power supply of industrial enterprises. - M .: "Energoatomizdat", 1995, 416 p.

2. Poskrobko A.A. Bratolyubov V. B. Non-contact switching and control semiconductor devices in alternating current. Moscow. Energy, p. 192, (1978).

3. Chopin L.V. - Contactless electrical automatic devices. M, Energoatomizdat, p. 446 (1986).

4. Patent RUz IAP № 03975, Non-contact device for switching the booster transformer windings. Kadirov T.M., Usmanov E.G., Abduraimov E.Kh. Publ. in "Official newsletter", 2009, № 7.pp 41-42.

5. Abduraimov E.Kh., Berdiev U.T., Burkhonkhodjaev O. M. Contactless switching devices. Bulletin of TashIIIZhT. Tashkent-2013, №. 1-2, -C.55 -59.

6. Abduraimov EK, Shamsutdinov X.F. Asamutdinov I.F. Non-contact voltage relay for automatic switching of capacitor units. Journal of Technical Science and Innovation TSTU 2019 №1 Pages 84-89

7. Abduraimov E.Kh. -Optoelectronic contactless switching devices. Bulletin of Tashkent State Technical University No. 3, 2016, pp. 73-78.

8. Bobojanov M.K., Usmanov E.G., Abduraimov E.Kh., Karimov R.Ch. Resistive time delay swishes Seintifie journal "European Science Review" Austria, Vienna, 2018 №1-2 210-212c PP210-212 (05.00.00; №3)

9. Abduraimov E.Kh., Khushiev S.M. Analysis of the load mode of a non-contact thyristor voltage relay. Bulletin of Tashkent State Technical University No. 4, 2007 p. 35-38
10. Abduraimov E. Kh., Khalmanov D. Kh. Theoretical analysis of semiconductor circuits. Eurasian Union of Scientists No. 3, 2019 Russia, pp. 60-63.

11. Abduraimov E.Kh., Halmanov D.Kh. Energy-saving contactless switching devices. International Conference "Problems of Improving the Efficiency of Using Electric Energy in the Agro-Industrial Complexes" Tashkent November 28, 2018 P -134-138.

12. Abduraimov E.Kh., Halmanov D.Kh., Khamidova N.E. Highly efficient and reliable contactless switching devices. Materials of the Republican Scientific and Technical Conf. "The integration of science, education and production is a major factor in the implementation of investment projects" Phil. Ross. Gos University N and G named. Gubkin. Tashkent -2019, P.247-249.

13. Abduraimov E. Kh., Khalmanov D.Kh. Dusmukhamedova S.A. Analysis of Semiconductor Circuits. International journal of Advanced Science and Technology. Vol.29 No. 11s (2020) 1655-1859.

14. Erkin Abduraimov. Research of the trigger effect in diode-thyristor circuits of contactless relay devices Rudenko International Conference "Methodological problems in reliability study of large energy systems" (RSES 2020).

15. Abduraimov E. Kh., Khalmanov D.Kh. Development of contactless solid state voltage relay // Rudenko International Conference "Methodological problems in reliability study of large energy systems" (RSES 2020).

16. Abduraimov E. Kh., Khalmanov D.Kh., Nurmatov B.A., S.A. Dusmukhamedova, Khamidova N.E. Theoretical research and development optoelectronic communication devices. Journal of Physics: Conference Series (JPCS) for further publishing.Conf.Series 1515022055 (2020). 